\title{
Polyenoic fatty acids and cholesterol in chicks given 9-cis-12-cis linoleate, 9-trans-12-trans linoleate or 9-trans-11-trans linoleate
}

\author{
By G. HØLMER, G. KRISTENSEN, E. SØNDERGAARD AND H. DAM \\ Danish Fat Research Institute and Department of Biochemistry and Nutrition, \\ Polytechnic Institute, Copenhagen
}

(Received 6 December 196I-Revised I6 February 1962)

We have previously studied the influence of dietary hydrogenated arachis oil on the deposition of polyenoic fatty acids and cholesterol in various tissues of chicks (Dam, Jart, Kristensen, Nielsen \& Søndergaard, 1958) and found mainly the same pattern of polyenoic fatty acids as with a fat-free diet. However, the content of nonconjugated trienoic acid in liver and heart was somewhat lower than in the fat-free groups.

The cholesterol contents of the organs examined were not influenced by dietary hydrogenated arachis oil when the diet was free from cholesterol.

In the experiments reported here, which were carried out in connexion with some studies on vitamin $\mathrm{E}$ deficiency, we fed chicks on a 'low-fat' diet containing $1.5 \%$ 9-cis-12-cis ethyl linoleate, I·5\% 9-trans-I I-trans ethyl linoleate, I·5\% 9-trans-I 2trans ethyl linoleate, respectively, and the low-fat diet itself in order to study the fate of these acids in the tissues and their influence on cholesterol metabolism. The designation 'low-fat' was chosen instead of 'fat-free' because one of the ingredients, Fleischmann yeast $5 \circ \mathrm{B}$, contained $3.8 \%$ total fatty acids.

\section{EXPERIMENTAL}

Day-old New Hampshire $\times$ White Leghorn chicks were given a commercial chicken mash (Karat, Karensmølle A/S, Copenhagen) for 8 days. They were then distributed into four groups with eleven chicks in each and given the experimental diets for 40 days. The compositions of the diets are shown in Table $\mathrm{I}$.

Further, each chick received the daily equivalent of $25^{\circ}$ i.u. vitamin A and 20 i.u. cholecalciferol as an ethanol-water solution stabilized with Tween 80 (polyoxyethylene sorbitan mono-oleate). This solution ( $0.1 \mathrm{ml}$ ) was given twice weekly.

At the end of the experiment the chicks were fasted (but had access to water ad lib.) for the last $20-22 \mathrm{~h}$ before decapitation. Just before the chick was killed, $2 \mathrm{ml}$ blood were taken from the jugular vein and heparinized with about $0.8 \mathrm{ml}$ heparin solution (5000 i.u. heparin $/ \mathrm{ml}$ ). The plasma was separated from the cells by centrifugation for $6 \mathrm{~min}$ at $1260 \mathrm{~g}$. The total cholesterol content of the plasma was determined by the method described by Herrmann (I957).

Liver, heart and brain were taken out and examined for polyenoic fatty acids, trans fatty acids and cholesterol. 
The tissues were saponified with $30 \%(\mathrm{w} / \mathrm{v})$ aqueous $\mathrm{KOH}(4 \mathrm{ml} / \mathrm{g}$ tissue) and $96 \%$ ethanol ( $\mathrm{r} \cdot 6 \mathrm{ml} / \mathrm{g}$ tissue) on a steam-bath for $2 \frac{1}{2} 3 \mathrm{~h}$. The unsaponifiable matter was extracted with diethyl ether. The extracts were washed with water, dried over anhydrous sodium sulphate and filtered. After filtration the extracts were taken to dryness under reduced pressure and dissolved in chloroform. Cholesterol was determined in a measured portion by the Liebermann-Burchard reaction.

Table $\mathbf{1}$. Composition of the diets $(\mathrm{g} / \mathrm{kg})$ (all vitamin E-free)

\begin{tabular}{|c|c|c|c|c|}
\hline \multirow[b]{2}{*}{ Ingredient } & \multicolumn{4}{|c|}{ Group no. } \\
\hline & 2335 & 2336 & 2337 & $234^{\circ}$ \\
\hline leischmann yeast $5 \circ \mathrm{B}^{*}$ & 400 & 400 & 400 & 400 \\
\hline elatin & 30 & 30 & 30 & 30 \\
\hline alt mixture no. $4 \dagger$ & $5+7$ & $5 I^{1} 7$ & $51 \cdot 7$ & $5 \mathrm{I} \cdot 7$ \\
\hline itamin mixture no. $4 \ddagger$ & $\mathrm{I}$ & I & 1 & I \\
\hline holine chloride & 2 & 2 & 2 & 2 \\
\hline ucrose & $500 \cdot 3$ & $500 \cdot 3$ & $500 \cdot 3$ & $515 \cdot 3$ \\
\hline -cis-12-cis ethyl linoleate§ & 15 & - & - & - \\
\hline -trans-I I-trans ethyl linoleate & 一 & I 5 & - & - \\
\hline -trans-12-trans ethyl linoleate & - & - & I5 & - \\
\hline kavit,** $\mathrm{I} \times$ ro $\mathrm{mg}$ & + & + & + & + \\
\hline
\end{tabular}

* From the Standard Brands Incorporated, New York, N.Y.; contained $3.8 \%$ total fatty acids and $0.8 \%$ of these were polyenoic fatty acids.

+ Consisted of: secondary calcium phosphate $\left(2 \mathrm{H}_{2} \mathrm{O}\right) 2800 \mathrm{~g}$, calcium carbonate $875 \mathrm{~g}$, desiccated magnesium sulphate (Ph.Dan.) $404 \mathrm{~g}$, potassium chloride (Ph.Dan.) $460 \mathrm{~g}$, sodium chloride (Ph.Dan.) $500 \mathrm{~g}$, ferric citrate (about $17.5 \% \mathrm{Fe}$ ) $100 \mathrm{~g}$, manganese sulphate (water-free) $23 \mathrm{~g}$, cupric sulphate $\left({ }_{5} \mathrm{H}_{2} \mathrm{O}\right)(P h . D a n) .2 \mathrm{~g}$, zinc sulphate $\left(7 \mathrm{H}_{2} \mathrm{O}\right)(P h . D a n$.$) I g, aluminium sulphate \left({ }_{1} 8 \mathrm{H}_{2} \mathrm{O}\right)(P h . D a n$. I g, magnesium silicate (Ph.Dan.) I g, diiodotyrosine (Ph.Dan.) I g, cobalt carbonate $0.05 \mathrm{~g}$; total $5168.05 \mathrm{~g}$.

I Consisted of: thiamine hydrochloride $3 \mathrm{mg}$, riboflavin $4 \mathrm{mg}$, nicotinic acid $50 \mathrm{mg}$, calcium pantothenate $12 \mathrm{mg}$, pyridoxine hydrochloride $3.5 \mathrm{mg}$, biotin $0.1 \mathrm{mg}$, folic acid $2.0 \mathrm{mg}$, sucrose $925.4 \mathrm{mg}$; total $1000 \cdot 0 \mathrm{mg}$.

$\S$ From the Hormel Institute, Austin, Minnesota. Analytical values for this ester were: iodine value 163.5 (theoretical 164.0 ), conjugated dienoic acid content $<0.07 \%$, conjugated trienoic acid content $<0.01 \%$.

II Prepared by Mr Aage Jart (Danish Fat Research Institute) from ricinoleic acid by elaidinization, dehydration and esterification. The purity was $97.5 \%$.

I From the Hormel Institute, Austin, Minnesota. The purity was $98 \%$. Ltd).

** Dicalcium salt of 2-methyl-I,4-naphthahydroquinone diphosphoric acid ester (Roche Products

Ph.Dan., Pharmacopoeia Danica, gth ed. Copenhagen 1948.

The residue from the diethyl ether extraction was acidified with conc. $\mathrm{HCl}$, and the liberated fatty acids were extracted with light petroleum. The extracts were combined, washed with water and dried over anhydrous sodium sulphate. After filtration, the light petroleum (b.p. $40-60^{\circ}$ ) extracts were evaporated to dryness under reduced pressure and analysed for polyethenoid structure by alkali isomerization, mainly as described by Hammond \& Lundberg (1953).

The trans fatty acids were determined by infrared spectrophotometry in a doublebeam instrument (Perkin-Elmer, Model 21). A solution of about $15 \%$ fatty acids in carbon disulphide was used for the measurements. The content of trans acids was determined by the base-line technique and calculated as percentage of elaidic acid. 


\section{RESULTS AND DISCUSSION}

\section{Weight gain}

The dietary supplement of 9-trans-I I-trans ethyl linoleate depressed the rate of weight gain to some extent. Thus, the mean values for weights after 5 weeks of experimental feeding were: for the low-fat group $20 \mathrm{I} \mathrm{g}$, for the 9-cis-12-cis ethyl linoleate group $\mathrm{I} 82 \mathrm{~g}$, for the 9-trans-12-trans ethyl linoleate group $173 \mathrm{~g}$, and for the 9-trans-I I-trans ethyl linoleate group $163 \mathrm{~g}$.

Table 2. Polyenoic fatty acids in liver, heart and brain of chicks, as percentage of total fatty acids

Type of acid

Dienoic
Trienoic
Tetraenoic
Pentaenoic
Hexaenoic
Preformed conjugated dienoic
$\quad$ Total polyenoic

Dienoic

Trienoic

Tetraenoic

Pentaenoic

Hexaenoic

Preformed conjugated dienoic

Total polyenoic

Dienoic
Trienoic
Tetraenoic
Pentaenoic
Hexaenoic
Preformed conjugated dienoic

Total polyenoic

\begin{tabular}{|c|c|c|c|}
\hline \multicolumn{4}{|c|}{ Group no. and dietary fat } \\
\hline $\begin{array}{c}2335 \\
\text { I.5\% 9-cis-12- } \\
\text { cis } \text { ethyl } \\
\text { linoleate }\end{array}$ & $\begin{array}{c}233^{6} \\
\text { I.5\% 9-trans- } \\
\text { I I-trans ethyl } \\
\text { linoleate }\end{array}$ & $\begin{array}{c}2337 \\
\text { I.5\% 9-trans- } \\
\text { I 2-trans ethyl } \\
\text { linoleate }\end{array}$ & $\begin{array}{c}234^{\circ} \\
\text { low-fat }\end{array}$ \\
\hline \multicolumn{4}{|c|}{ Liver } \\
\hline $14 \cdot 6$ & $5 \cdot \mathrm{I}$ & $2 r \cdot 8$ & 4.7 \\
\hline 0.6 & $4 \cdot 5$ & $2 \cdot 1$ & $9^{\cdot 6}$ \\
\hline $21 \cdot 5$ & 3.6 & $4 \cdot 0$ & $6 \cdot 1$ \\
\hline $2 \cdot 4$ & 0.8 & 0.8 & $I \cdot I$ \\
\hline $\mathrm{I} \cdot 5$ & 0.8 & 0.7 & $I \cdot I$ \\
\hline $1 \cdot 2$ & $4 \cdot 8$ & 0.7 & 0.8 \\
\hline $4 x \cdot 8$ & $19 \cdot 6$ & $30 \cdot 1$ & $23 \cdot 4$ \\
\hline \multicolumn{4}{|c|}{ Heart } \\
\hline 14.4 & $6 \cdot 9$ & $17 \cdot 0$ & $6 \cdot 5$ \\
\hline 0.7 & $3 \cdot 5$ & $I \cdot 5$ & $7 \cdot 8$ \\
\hline $17 \cdot 5$ & $5 \cdot 3$ & $5 \cdot 3$ & $6 \cdot 4$ \\
\hline$I \cdot 4$ & 0.6 & 0.5 & 0.6 \\
\hline 0.4 & 0.2 & 0.3 & 0.3 \\
\hline$I \cdot 5$ & $3 \cdot 2$ & 0.8 & 0.6 \\
\hline $35 \cdot 9$ & $19 \cdot 7$ & $25 \cdot 4$ & $22 \cdot 2$ \\
\hline \multicolumn{4}{|c|}{ Brain } \\
\hline 0.3 & $0 \cdot 2$ & $2 \cdot 6$ & 0.2 \\
\hline$I \cdot 2$ & $5 \cdot 1$ & $4 \cdot 0$ & $5 \cdot 4$ \\
\hline $10 \cdot 2$ & $6 \cdot 6$ & $7 \cdot 4$ & $7 \cdot 5$ \\
\hline 3.9 & $2 \cdot 1$ & $2 \cdot 0$ & 2.4 \\
\hline $6 \cdot 7$ & $6 \cdot 7$ & $6 \cdot 9$ & $7 \cdot 1$ \\
\hline$x \cdot 0$ & $2 \cdot 2$ & $1 \cdot 0$ & 0.9 \\
\hline 23.7 & $22 \cdot 9$ & $23 \cdot 9$ & $23 \cdot 5$ \\
\hline
\end{tabular}

Each value represents the mean for eight determinations.

\section{Polyunsaturated fatty acids (Table 2)}

Liver. The low-fat diet caused typical accumulation of trienoic acid together with fair amounts of dienoic and tetraenoic acids, whereas pentaenoic and hexaenoic acids were present in smaller amounts. The content of preformed conjugated dienoic acid is given separately in Table 2 and was less than $\mathbf{I} \%$.

9 -cis- $\mathrm{I} 2$-cis ethyl linoleate ( $\mathrm{I} \cdot 5 \%$ of the diet) increased the amount of conjugatable dienoic acid considerably and gave rise to a marked deposition of the conversion 
product, arachidonic acid, whereas the value for trienoic acid was depressed almost to zero.

The contents of penta- and hexa-enoic acids were slightly increased compared with the values obtained on the low-fat diet. That of preformed conjugated dienoic acid was, similarly, slightly increased.

The liver fatty acids from chicks given $1 \cdot 5 \%$ 9-trans-II-trans ethyl linoleate showed a distinct accumulation of trienoic acid, although less than those from the low-fat group. This may be a sign of the inability of the conjugated trans-trans acid to act as essential fatty acid (EFA). The ratio trienoic:tetraenoic acids (considered by Holman (I960) as a measure of EFA deficiency) was about $I \cdot 60$ for the low-fat group and $\mathrm{I} \cdot 25$ for the group receiving 9-trans-I I-trans ethyl linoleate. Similarly, AaesJørgensen (1958) has found deposition of trienoic fatty acids in the heart and testis of rats fed on diets containing I \% trans-trans ethyl linoleate.

The value for preformed conjugated dienoic acid in the liver fat was, as might be expected, much higher than for the other groups. This finding means that dietary 9-trans-I I-trans ethyl linoleate can be absorbed and deposited in the body. The figures for tetra-, penta- and hexaenoic acids indicate that 9-trans-II-trans ethyl linoleate had not been converted into conjugatable acids of higher degree of unsaturation.

The livers of the chicks given $1 \cdot 5 \%$ 9-trans-12-trans linoleate showed a very interesting pattern of EFA. The content of dienoic acid, probably 9-trans-12-trans linoleate, was even higher than that of dienoic acid in liver fat from the corresponding group with $\times \cdot 5 \%$ dietary 9 -cis-12-cis linoleate. However, the presence of some trienoic acid (about $2 \cdot 1 \%$ ) indicated that there was some lack of EFA, although not to the same marked degree as in the group receiving the low-fat diet. It may have been due to a sparing effect of the 9-trans-12-trans linoleate on 9-cis-12-cis linoleate.

It is evident that conversion into arachidonic acid did not occur. The amount of tetraenoic acid found was most likely present in the chick before the experimental feeding. The failure to form tetraenoic acid might be due to steric hindrance caused by the trans double bonds or, more likely, to the specificity of the enzyme system in the chick liver.

The content of penta- and hexa-unsaturated acids was similar to that found for the low-fat group and not as high as for the 9-cis-12-cis linoleate group. The conversion into these acids also seemed inhibited.

In contrast to the results for the different organs of chicks, Holman (I95 I) reported that there was an increase in tetraenoic and hexaenoic acids of total carcass fat in rats fed on linolelaidate (trans-trans linoleate).

That the low value for tetraenoic acid found in our experiments was not simply due to slow isomerization of trans-trans double bonds was ascertained by examining the influence of longer isomerization times on the specific absorption at $3^{\mathrm{I}} 5 \mathrm{~m} \mu$.

A gas chromatographic study of the same problem was also made. The pooled liver fatty acids from the 9-trans-I 2-trans linoleate group were converted into methyl esters, which were then separated on columns of succinate polyester $\left(\frac{1}{4}\right.$ in. $\left.\times 6 \mathrm{ft}\right)$ and silicone grease $\left(\frac{1}{4} \mathrm{in} . \times 6 \mathrm{ft}\right)$. Only small amounts of $\mathrm{C}_{20}$ unsaturated acids were found, 
indicating that conversion of trans linoleate into trans arachidonate did not take place. The small amount observed must have represented $C_{20}$ acids present before the experimental diet was given.

Exclusion of vitamin $\mathrm{E}$ from the diet does not seem to have influenced the interconversion processes. In our experiments, the diet with $1 \cdot 5 \% 9$-cis-I2-cis ethyl linoleate caused nearly the same distribution and conversions as had been found in our laboratory when the same diets were supplemented with vitamin $\mathrm{E}$ (unpublished results).

Heart. The distribution of polyenoic fatty acids was nearly the same as described for liver, the only exception being that $\mathrm{I} \cdot 5 \%$ 9-trans-I I-trans ethyl linoleate caused a less marked deposition of trienoic acid in the heart than in the liver, whereas the corresponding values for dienoic and tetraenoic acids were somewhat higher. The ratio trienoic: tetraenoic acids was only $0 \cdot 66$, against $1 \cdot 22$ for the low-fat group.

The difference between liver and heart in this respect may be related to the different functions of these organs, the liver being an organ in which conversion processes predominantly take place and the heart an organ in which some of the conversion products are deposited later. The content of preformed conjugated dienoic acid was high after ingestion of 9-trans-I I-trans ethyl linoleate, as was also found for liver. (This finding differs from that of Aaes-Jørgensen (1958) with rats in which deposition of preformed conjugated dienoic acid was high in adipose tissue but not in heart, brain or testis.)

Brain. As a sign of EFA deficiency the values for trienoic acid in the low-fat animals were elevated. The contents of tetraenoic and hexaenoic acids were high, as always in brain. Also the values found for pentaenoic acid were somewhat higher than in the other tissues, whereas dienoic acid was almost absent.

Almost the same pattern was found when 9-trans-I I-trans ethyl linoleate was given, but then the value for preformed conjugated dienoic acid was increased, as in the organs mentioned.

When $1 \cdot 5 \%$ 9-cis-r2-cis ethyl linoleate was given, the amount of dienoic acid was almost unchanged, of trienoic decreased and of tetraenoic and pentaenoic increased. Hexaenoic acid was unchanged in amount or slightly decreased, compared with the low-fat group. The ratio trienoic:tetraenoic acid was only 0.12 against 0.72 for the low-fat group.

Finally, the giving of 9-trans-I2-trans ethyl linoleate showed that some dienoic acid was deposited, contrary to what was found in all the other groups. The determinations of trans acids further described below showed that about $2-3 \%$ of trans fatty acids calculated as elaidic acid were present in this group, suggesting that the dienoic acid found by isomerization was, at least in part, the 9-trans-12-trans acid.

The content of trienoic acid was nearly the same as for the low-fat group or slightly lower, indicating that the 9-trans-12-trans ethyl linoleate had only a small effect as EFA, if any at all. The higher polyenes (tetra-, penta- and hexa-) reached the same values as for the low-fat group. 


\section{Trans fatty acids (Table 3)}

Livers. In the livers from the groups receiving either the low-fat diet or $1.5 \%$ 9-cis-12-cis ethyl linoleate, no trans fatty acids were detected.

Fatty acids from chicks receiving 9-trans-I I-trans ethyl linoleate showed a peak at $986 \mathrm{~cm}^{-1}\left(\right.$ IO $\mathrm{I}_{4} \mu$ ), corresponding to conjugated trans double bonds, whereas any absorption maximum at $967 \mathrm{~cm}^{-1}(10 \cdot 35 \mu)$ from isolated double bonds was absent. The trans peak represented, when calculated as elaidic acid, I I $\%$ of the total fatty acids.

Table 3. Trans fatty acids in liver and brain of chicks (pooled for each group), expressed as percentage of elaidic acid in total fatty acids

\begin{tabular}{|c|c|c|c|c|}
\hline & \multicolumn{4}{|c|}{ Group no. and dietary fat } \\
\hline Type of acid & $\begin{array}{c}2335 \\
\mathrm{I} \cdot 5 \% 9 \text {-cis- } \\
\mathrm{I} 2-\text {-cis ethyl } \\
\text { linoleate }\end{array}$ & $\begin{array}{c}2336 \\
\text { I.5\% 9-trans- } \\
\text { I I-trans } \text { ethyl } \\
\text { linoleate }\end{array}$ & $\begin{array}{c}2337 \\
\text { I.5\% 9-trans- } \\
\text { 12-trans ethyl } \\
\text { linoleate }\end{array}$ & $\begin{array}{c}2340 \\
\text { low-fat }\end{array}$ \\
\hline \multicolumn{5}{|c|}{ Liver } \\
\hline Isolated trans & $\circ$ & $\circ$ & 29 & o \\
\hline Conjugated trans & $\circ$ & I I & 0 & $\circ$ \\
\hline Total trans & $\circ$ & II & 29 & $\circ$ \\
\hline \multicolumn{5}{|c|}{ Brain } \\
\hline Isolated trans & 0 & 0 & $2-3$ & 0 \\
\hline Conjugated trans & 0 & 0 & o & $\circ$ \\
\hline Total trans & 0 & o & $2-3$ & o \\
\hline
\end{tabular}

The liver fatty acids from the chicks in the group receiving 9-trans-12-trans ethyl linoleate showed a high peak at $967 \mathrm{~cm}^{-1}(10 \cdot 35 \mu)$ due to isolated bonds. No peak for conjugated trans compounds was present at $986 \mathrm{~cm}^{-1}(\mathrm{I} 0 \cdot 14 \mu)$.

The absorption maximum found was equivalent to $29 \%$ trans fatty acids (calculated as elaidic acid).

Brain. In the brain, trans fatty acids were present only in chicks from the group that had received $\mathrm{I} \cdot 5 \%$ 9-trans-I2-trans ethyl linoleate. In this group, a peak at $967 \mathrm{~cm}^{-1}(10.35 \mu)$ corresponded to about $2-3 \%$ trans fatty acids.

No detectable amount of trans acid was found in the group receiving conjugated trans bonds in the form of 9-trans-I I-trans ethyl linoleate. This is in contrast to the deposition of this acid in the liver.

The finding that the 9-trans-I2-trans isomer of linoleic acid, but not linoleic acid itself, can be deposited in the brain seems surprising and requires further study.

\section{Cholesterol}

The (fasting) cholesterol contents of plasma, liver, heart and brain are shown in Table 4.

Plasma. There was no significant difference between the plasma cholesterol contents of the four groups in this experiment, but $\mathrm{x} \cdot 5 \%$ 9-cis-12-cis ethyl linoleate tended to give a lower average value than did the other fats. 
This finding resembles that in a similar experiment (not published) with chicks receiving diets containing vitamin $\mathrm{E}$. Here also we found no significant difference in the plasma cholesterol concentrations of a low-fat group and of a group fed on a diet supplemented with $\mathrm{I} \cdot 5 \%$ 9-cis-12-cis ethyl linoleate.

Table 4. Mean values with their standard errors for (fasting) cholesterol contents of plasma, liver, heart and brain of chicks, expressed as $\mathrm{mg} / \mathrm{1} 00 \mathrm{ml}$ plasma and $\mathrm{mg} / \mathrm{1} 00 \mathrm{~g}$ tissue

\begin{tabular}{|c|c|c|c|c|c|}
\hline $\begin{array}{c}\text { Group } \\
\text { no. }\end{array}$ & Dietary fat & Plasma & Liver & Heart & Brain \\
\hline 2335 & $\begin{array}{l}\text { I. } 5 \% \text { 9-cis-12-cis } \\
\text { ethyl linoleate }\end{array}$ & $144(11) \pm 14$ & $321(10) \pm 13$ & $155(9) \pm 19$ & $1206(9) \pm 21$ \\
\hline 2336 & $\begin{array}{l}\text { I. } 5 \% \text { 9-trans-II- } \\
\text { trans ethyl } \\
\text { linoleate }\end{array}$ & $182(11) \pm 13$ & $592(8) \pm 3 I$ & I $56(9) \pm I 5$ & $1164(9) \pm 32$ \\
\hline 2337 & $\begin{array}{l}\text { I. } 5 \% \text { 9-trans-12- } \\
\text { trans ethyl } \\
\text { linoleate }\end{array}$ & $174(\mathrm{II}) \pm \mathrm{I} 7$ & $710(10) \pm 60$ & $224(9) \pm$ I I & I $185(8) \pm 29$ \\
\hline 2340 & None & $171(I I) \pm 8$ & $455(10) \pm 26$ & $156(10) \pm 9$ & $1088(9) \pm 47$ \\
\hline
\end{tabular}

Numbers in parentheses show the numbers of animals in each group.

Liver. The group fed on a diet containing $1.5 \%$ 9-cis-12-cis ethyl linoleate had a significantly lower liver cholesterol content $(P<0.001)$ than the three other groups receiving the low-fat diet, $\mathrm{I} \cdot 5 \%$ 9-trans-I I-trans ethyl linoleate or $\mathrm{I} \cdot 5 \%$ 9-trans-I2trans ethyl linoleate. Both I.5\% 9-trans-II-trans ethyl linoleate and I.5\% 9-transI2-trans ethyl linoleate caused significantly higher liver cholesterol contents than did the low-fat diet, but there was no significant difference between the liver cholesterol contents of the groups fed on these two fats.

Heart. The hearts of the groups receiving $\mathrm{r} \cdot 5 \%$ 9-cis-I2-cis ethyl linoleate, $\mathrm{I} \cdot 5 \%$ 9-trans-I I-trans ethyl linoleate and the low-fat diet had the same cholesterol level, significantly lower than that of the group receiving $1 \cdot 5 \%$ 9-trans-12-trans ethyl linoleate.

The finding that $1 \cdot 5 \%$ 9-trans-12-trans ethyl linoleate had an elevating effect on cholesterol content in liver and heart, but not in plasma, resembles the results of an earlier experiment with chicks receiving 10\% hydrogenated arachis oil containing $46 \%$ trans acid, calculated as elaidic acid (Hølmer, Kristensen, Søndergaard \& Dam, 1960).

Brain. As would be expected, there was no significant difference in brain cholesterol between the four groups.

\section{SUMMARY}

I. The deposition of polyenoic fatty acids, total trans fatty acids and cholesterol in chicks after feeding on a low-fat diet alone or supplemented with $1 \cdot 5 \%$ 9-cis-12-cis ethyl linoleate, I·5\% 9-trans-II-trans ethyl linoleate or 1.5\% 9-trans-I2-trans ethyl linoleate was studied.

2. In the liver and heart of chicks, the giving of $1.5 \%$ 9-trans-I I-trans ethyl 
linoleate caused deposition of trienoic acid, as found in essential fatty acid deficiency, and the value for preformed conjugated dienoic acid was much higher than in groups fed on a low-fat diet or a diet containing 9-cis-12-cis ethyl linoleate.

Chicks receiving 9-trans-12-trans ethyl linoleate had a high content of dienoic acid in liver and heart, probably 9-trans-12-trans linoleate, but conversion into a transarachidonic acid did not occur.

3. In the brain, 9-cis-I2-cis ethyl linoleate gave an increased content of arachidonic acid and a decreased amount of trienoic acid, compared with the groups fed on the low-fat diet, I.5\% 9-trans-II-trans ethyl linoleate or $1 \cdot 5 \%$ 9-trans-12-trans ethyl linoleate. The group receiving 9-trans-12-trans ethyl linoleate showed some conjugatable dienoic acid present, but it was nearly absent from the other three groups.

4. Trans fatty acids were found in the liver of chicks receiving either 9-trans-I Itrans ethyl linoleate or 9-trans-12-trans ethyl linoleate, but in the brain only the latter gave rise to detectable amounts of trans fatty acids.

5. No effect of the dietary fats was found on the plasma and brain cholesterol contents.

6. In the liver, both $\mathbf{I} \cdot 5 \%$ 9-trans-I2-trans ethyl linoleate and $1 \cdot 5 \%$ 9-trans-I Itrans ethyl linoleate caused significantly higher cholesterol levels than did $\mathrm{I} \cdot 5 \%$ 9-cis-12-cis ethyl linoleate; 9-trans-12-trans ethyl linoleate gave the highest liver cholesterol value.

7. In the heart, cholesterol content was affected only by the diet containing $\mathrm{x} \cdot 5 \%$ 9-trans-12-trans ethyl linoleate, which caused a significant increase compared with the other diets.

\section{REFERENCES}

Aaes-Jørgensen, E. (1958). F. Nutr. 66, 465 .

Dam, H., Jart, Aa., Kristensen, G., Nielsen, G. K. \& Søndergaard, E. (1958). Acta physiol. scand. 43, 97.

Hammond, E. G. \& Lundberg, W. O. (1953). F. Amer. Oil Chem. Soc. 30, 433 .

Herrmann, R. G. (1957). Proc. Soc. exp. Biol., N.Y., 94, 503.

Holman, R. T. (r95 I). Proc. Soc. exp. Biol., N.Y., 76, 100.

Holman, R. T. (1960). F. Nutr. 70, 405.

Hølmer, G., Kristensen, G., Søndergaard, E. \& Dam, H. (I960). Brit. F. Nutr. 14, 247. 